\title{
Nerve Growth Factor Accelerates Seizure Development, Enhances Mossy Fiber Sprouting, and Attenuates Seizure-Induced Decreases in Neuronal Density in the Kindling Model of Epilepsy
}

\author{
Beth Adams, ${ }^{1}$ Mona Sazgar, ${ }^{2}$ Philip Osehobo, ${ }^{2}$ Catharina E. E. M. Van der Zee, ${ }^{3}$ Jack Diamond, ${ }^{2}$ \\ Margaret Fahnestock, ${ }^{2}$ and Ronald J. Racine ${ }^{1}$ \\ ${ }^{1}$ Department of Psychology and ${ }^{2}$ Department of Biomedical Sciences, McMaster University, Hamilton, Ontario, Canada \\ L8S 4K1, and ${ }^{3}$ Department of Anatomy, Dalhousie University, Halifax, Nova Scotia, Canada
}

\begin{abstract}
Recurrent seizure activity induced during kindling has been reported to produce a functional synaptic reorganization of the mossy fibers in the hippocampus. To date, it is unclear whether this kindling-induced growth is secondary to decreases in hilar neuron density, which are presumed to reflect hilar neuronal cell loss, or whether it is related specifically to an activationdependent plasticity. We recently demonstrated that blocking nerve growth factor (NGF) biological activity retards seizure development and inhibits the sprouting of mossy fibers. We now demonstrate that intraventricular administration of NGF itself accelerates the progression of kindling epileptogenesis, increases mossy fiber sprouting in the CA3 region and in the
\end{abstract}

inner molecular layer (IML), but reduces seizure-induced decreases in hilar cell density. These findings provide support for a role of NGF in kindling and kindling-induced mossy fiber sprouting. In addition, the results dissociate this form of epileptogenesis from hilar cell loss or decreases in hilar cell density attributable to increases in hilar area, thereby supporting seizure-induced mossy fiber sprouting as being primarily attributable to the combined effects of neuronal activation and the activation-induced upregulation of growth factors.

Key words: nerve growth factor (NGF); kindling; synaptic reorganization; mossy fiber sprouting; epilepsy; plasticity; neurotrophin
Kindling is an experimental epilepsy model in which repeated electrical stimulation of certain forebrain structures triggers progressively more intense electroencephalographic and behavioral seizure activity (Goddard et al., 1969; Racine, 1972). Once established, kindling results in a permanent state of seizure susceptibility, which may include spontaneous epileptiform seizures (Pinel and Rovner, 1978). Kindling recently has been shown to induce a variety of permanent structural changes in the brain, including sprouting of the mossy fiber pathway that originates from the hippocampal dentate gyrus granule cells (Sutula et al., 1988; Represa et al., 1989; Cavazos et al., 1991) and neuronal loss in specific populations of limbic neurons, particularly of hilar cells in the hippocampus (Cavazos and Sutula, 1990; Cavazos et al., 1994).

The relationship between kindling-induced sprouting and neuronal loss in the hippocampus is currently unclear (Sutula et al., 1992). It has been suggested that kindling produces hilar cell loss and that the mossy fibers may sprout as a secondary consequence of axonal degeneration in their target regions (Cronin et al., 1992). Thus, hippocampal hilar neuronal loss may be a cause and an effect of recurrent seizures by promoting the development of recurrent excitatory connections in dentate granule cells. However, kindling-induced mossy fiber sprouting also has been reported in the absence of any noticeable hippocampal neuronal

\footnotetext{
Received Dec. 4, 1996; revised April 28, 1997; accepted May 1, 1997.

This work was supported by grants from the Neuroscience Networks Centers of Excellence (NCE) (R.J.R., M.F., J.D.), the Natural Sciences and Engineering Research Council of Canada (NSERC) (R.J.R.), and the Medical Research Council of Canada (R.J.R., M.F.). B.A. was supported by a postgraduate scholarship from NSERC (PGS B) and a supplement from the NCE. We thank Karmen Bleile and Nicholas Adams for technical assistance.

Correspondence should be addressed to Dr. R. J. Racine, Department of Psychology, McMaster University, Hamilton, Ontario, Canada L8S 4K1.

Copyright (C) 1997 Society for Neuroscience $0270-6474 / 97 / 175288-09 \$ 05.00 / 0$
}

loss or degeneration (Represa et al., 1989, 1993; Represa and Ben-Ari, 1992). Alternatively, it is possible that kindling-induced mossy fiber sprouting may be triggered by neuronal activation. In either case, cell loss or activation, sprouting may be regulated by growth factors (Diamond et al., 1992).

To address these issues, we have capitalized on recent experimental evidence implicating neurotrophic factors in kindling epileptogenesis and kindling-induced mossy fiber sprouting. Because neurotrophic factors can exert morphoregulatory effects on hippocampal neurons (Mattson et al., 1989; Ip et al., 1993; Patel and McNamara, 1995), it has been proposed that seizure-induced expression of neurotrophic genes may underlie the sprouting of the axons of the dentate granule cells (Watanabe et al., 1996). Certainly, seizure activity can increase nerve growth factor (NGF) mRNA expression (Gall and Isackson, 1989; Ernfors et al., 1991) and NGF protein levels (Bengzon et al., 1992) in cortical and hippocampal neurons. Furthermore, blocking NGF activity not only retards amygdaloid kindling (Funabashi et al., 1988; Rashid et al., 1995; Van der Zee et al., 1995) but also inhibits mossy fiber sprouting (Rashid et al., 1995; Van der Zee et al., 1995). Together, these findings strongly support the possibility that increased levels of NGF in the target region of the mossy fibers may play a role in kindling-induced mossy fiber sprouting and may contribute to further seizure development. However, kindling-induced neuronal loss was not investigated in these studies.

Increased levels of NGF could occur as a consequence of partial deafferentation of the granule cells, a concept well established in other sprouting paradigms (Diamond et al., 1976; Diamond, 1982). Because neurotrophins also can promote cell survival (Eide et al., 1993), there is the possibility that neurotrophin administration might protect hilar cells from damage and thereby provide a tool for dissociating kindling-induced hilar cell loss and kindling- 
induced sprouting. In this study we tested the hypothesis that the pairing of activation and NGF would enhance mossy fiber sprouting while reducing the decreases in hilar cell density associated with the kindling. The results support kindling-induced mossy fiber sprouting as being attributable to the coinvolvement of neuronal activation and growth factors rather than to the degeneration of hilar cells.

\section{MATERIALS AND METHODS}

Animals and surgical procedures. Adult male Long-Evans hooded rats ( $n=36)$ weighing between 300 and $400 \mathrm{gm}$ were used. Rats were maintained on an ad libitum feeding schedule, housed individually, and kept on a $12 \mathrm{hr}$ on/12 hr off light cycle. Using stereotaxic procedures, we anesthetized rats with sodium pentobarbital $(65 \mathrm{mg} / \mathrm{kg})$ and implanted a bipolar electrode made from Teflon-coated, stainless steel wires (diameter, $190 \mu \mathrm{m}$ ) in the right amygdala. Stereotaxic coordinates (Paxinos and Watson, 1985) were $2.8 \mathrm{~mm}$ posterior and $4.8 \mathrm{~mm}$ lateral to bregma and $8.6 \mathrm{~mm}$ ventral to brain surface. After electrode implantation, a cannula was implanted into the right lateral ventricle at $0.6 \mathrm{~mm}$ posterior and $1.3 \mathrm{~mm}$ lateral to bregma and $5 \mathrm{~mm}$ below the skull surface. To confirm correct placement of the electrode and cannula, we conducted a histological examination of coronal sections containing the lateral ventricle or the amygdala at the beginning of the experiment $(n=4)$. Both the electrode and the cannula were held in place by dental acrylic and three stainless steel screws inserted into the skull. A flow-regulated mini-osmotic pump (Alzet model 2002) was connected to the cannula via $3.5 \mathrm{~cm}$ of polyethylene tubing. To prolong the effectiveness of the pump, we coated the bottom third of each pump in paraffin before implantation (Vahlsing et al., 1989). This served to reduce the flow rate of the pump from $12 \mu \mathrm{l} / \mathrm{d}$ to $\sim 9 \mu \mathrm{l} / \mathrm{d}$, making the pump effective for an additional $7 \mathrm{~d}$. The pump was placed subcutaneously in the dorsal neck/back region, and it delivered either PBS, $\mathrm{pH} 7.2$, or $2.5 \mathrm{~S}$ NGF $(1 \mathrm{mg} / \mathrm{ml}$ in PBS). An additional control group received cytochrome C $(1 \mathrm{mg} / \mathrm{ml}$ in PBS), a protein similar in size and charge to NGF. Animals were given $7 \mathrm{~d}$ to recover from surgery before the kindling protocol was initiated. Solutions were inf used at a rate of $9 \mu \mathrm{g} / \mathrm{d}$ for $18 \mathrm{~d}$, beginning on the day of surgery and ending on the last day of the kindling protocol. Thus, animals in the kindled NGF-inf used group were pretreated with a total of $63 \mu \mathrm{g}$ of NGF $(9 \mu \mathrm{g} / \mathrm{d}$ for $7 \mathrm{~d})$ before the initiation of kindling. Because of a lack of availability of NGF, the NGF-infused nonkindled group was not run during the same experimental period as the other five groups.

Preparation of $2.5 \mathrm{~S} \mathrm{NGF}$. 2.5 S NGF was isolated from male mouse salivary glands according the procedure of Mobley et al. (1976). The purified protein migrated as a doublet at $13.5 \mathrm{kDa}$ in SDS-PAGE gels. Biological activity was measured in a dissociated cell assay (Coughlin and Collins, 1985) by using neonatal mouse dorsal root ganglion neurons.

Kindling paradigm. Rats were stimulated twice daily, with interstimulus intervals of at least $6 \mathrm{hr}$, for a total of $11 \mathrm{~d}$. Each stimulation comprised a $1 \mathrm{sec}$ train of $1 \mathrm{msec}$ pulses at a frequency of $60 \mathrm{~Hz}$ and a pulse intensity ranging from 500 to $600 \mu \mathrm{A}$. This was sufficient to trigger epileptiform afterdischarges (ADs) of $>5 \mathrm{sec}$ after each stimulation. The durations of the ADs were recorded in electroencephalograph (EEG) recordings from the amygdala electrode. Although it may have been useful to record $\mathrm{AD}$ duration directly in the hippocampus, as compared with the amygdala, the damage caused by a recording electrode in the hippocampus would have interfered substantially with subsequent histological analyses. Furthermore, there is evidence demonstrating that electrophysiological data recorded from the amygdala accurately reflect electrographic seizure propagation in the hippocampus (Racine, 1972; Watanabe et al., 1996). An experimenter blind to the experimental conditions monitored the progression of kindling by recording the behavioral seizure stage after each stimulation according to Racine's classification (1972): (1) mouth and facial twitches, (2) clonic head movements, (3) unilateral forelimb clonus followed by contralateral clonus, (4) clonic rearing, and (5) loss of postural control. Animals were regarded as fully kindled when they exhibited three consecutive stage 5 seizures. Nonkindled, implanted controls remained in the colony for $18 \mathrm{~d}$.

Histological analyses. At day 18 after surgery, rats were anesthetized with sodium pentobarbital $(65 \mathrm{mg} / \mathrm{kg})$ and were perfused transcardially with $50 \mathrm{ml}$ of a sodium sulfide solution $\left(8.9 \mathrm{gm}\right.$ of $\mathrm{Na}_{2} \mathrm{~S} \cdot 9 \mathrm{H}_{2} \mathrm{O}, 10.9 \mathrm{gm}$

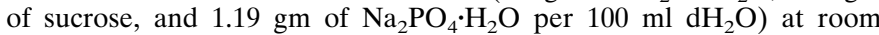
temperature. Kindled rats were perfused immediately after the last kindling stimulation. After perfusion the brains were removed, covered with Tissue-Tek (Miles, Diagnostics Division, Elkhart, IN), and immediately frozen on dry ice. Horizontal serial $40 \mu$ sections of the hippocampal area at $4.28-7.6 \mathrm{~mm}$ ventral to bregma were sectioned with a cryostat at $-18^{\circ} \mathrm{C}$ and mounted on chromium potassium sulfate-coated slides. Section depth was determined by using an atlas, The Rat Brain in Stereotaxic Coordinates (Paxinos and Watson, 1985). Alternate sections were stained with either a modified Timm method (Sutula et al., 1988; Van der Zee et al., 1995) for the analysis of mossy fiber sprouting or cresyl violet for the determination of neuronal cell number. To ensure that brain sections included in the data analysis were from comparable levels, we selected six sections of the hippocampal area at $4.6-7.34 \mathrm{~mm}$ ventral to bregma and $200 \mu$ apart from each brain across all rats. So that objectivity in data analysis could be ensured, slides were coded and all subsequent analyses were done by an observer who was unaware of the treatment of the animal.

The Timm method stains neural elements containing heavy metals (i.e., the high $\mathrm{Zn}^{2+}$ content of the terminals of the mossy fiber axons of the dentate granule cells). To minimize variability in Timm staining among groups, we processed sections from animals from different groups simultaneously. Slides for the NGF-inf used nonkindled group were processed at a later time.

Horizontal sections from the dorsal dentate gyrus were examined at $50 \times$ magnification by creating a digitized image with a Micro Computer Imaging Device (MCID) image analysis system (Brock University, St. Catherines, Ontario, Canada) attached to a light microscope (Zeiss Axioskop, Oberkochen, Germany) with a high-resolution charge-coupled device (CCD) camera (MTI CCD 72). Sites of measurement of Timm granule density were determined at geographically predetermined sites (see Fig. $3 A$ ). The density of Timm granules in the CA3 region was measured by placing an open circle cursor $\left(0.013 \mathrm{~cm}^{2}\right)$ at 16 adjacent positions along the stratum oriens of the CA3, as described by Van der Zee et al. (1995) (see Fig. $3 A$ ), and the density of Timm granules in the inner molecular layer (IML) was measured at nine adjacent cursor positions by placing one cursor position above the genu of the hilus and four cursor positions to the right and left of this cursor (see Fig. 5A). Background values were provided by readings at eight cursor placements in the stratum radiatum of the $\mathrm{CA} 3$, as described by Van der Zee et al. (1995) (see Fig. 3A). To control for variations in background Timm staining density from section to section, we divided the density readings in the stratum oriens and the IML by the background density values from the stratum radiatum for each section. This provided a ratio between the stratum oriens or the IML density value and the stratum radiatum density value per section for all experimental groups. Density measurements were evaluated from six brain sections per rat at different section levels for both the right and left sides of the brain.

Cresyl violet staining and measurement of hilar cell density and hilar area. Cresyl violet selectively stains Nissl substance, a characteristic granular substance found in the nerve cell body. Hilar cell density was evaluated with a light microscope (Zeiss Axioskop) with a camera lucida attachment. Horizontal sections from the dentate gyrus were examined at $400 \times$ magnification. Using the camera lucida attachment, we positioned an unbiased counting grid $(200 \times 265 \mu)$ in the hilus perpendicular to the CA3/CA4 region, and we manually circled and counted cells with visible nuclei containing a nucleolus within the grid. Neuronal numbers within the grid were evaluated from six brain sections per rat at different section depths for both the right and left sides of the brain. Focus was varied as required to count all cells within the grid.

Recent experimental evidence suggests that the observed reduction in hilar neuron density may not be attributable to actual neuronal loss but, instead, may be attributable to a kindling-induced increase in hilar area (Bertram and Lothman, 1993; Watanabe et al., 1996). To examine this possibility, we examined digitized images of the horizontal cresyl violetstained sections used for the evaluation of hilar neuronal density at $50 \times$ magnification, using the MCID imaging system attached to a light microscope with a CCD camera, and we calculated area measurements of each hilus. Hilar area was defined by the inner edge of the granule cell layer and the lines connecting the tips of the two granule cell blades to the beginning of the pyramidal cell layer of Ammon's horn (Bertram and Lothman, 1993) (see Fig. 7A).

\section{RESULTS}

\section{Behavioral progression of kindling}

A repeated measures ANOVA was conducted to evaluate the behavioral progression of kindling in the PBS-, cytochrome C-, 

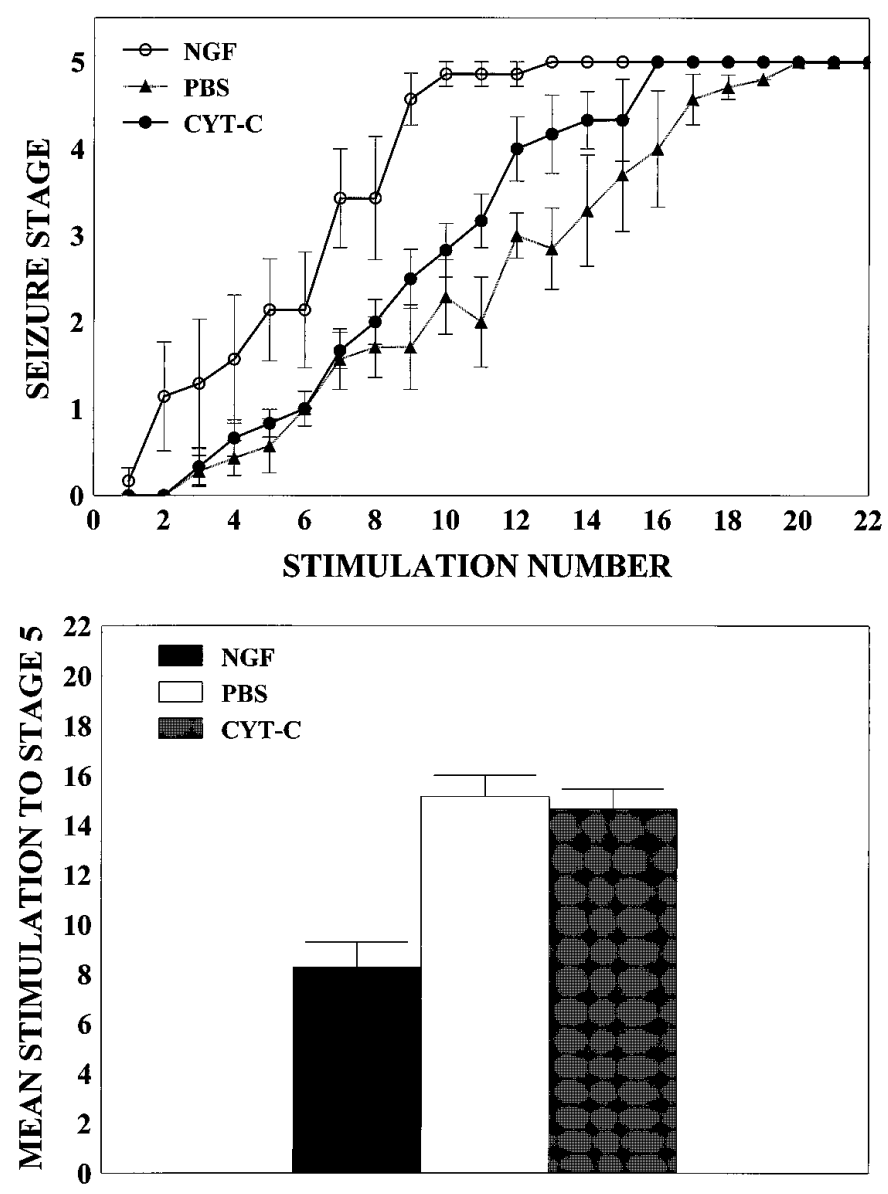

Figure 1. Behavioral progression of seizure activity. A, NGF administration accelerates the behavioral progression of kindling. Values represent mean seizure stage \pm SEM for NGF-kindled $(N G F ; n=7)$, cytochrome C-kindled (CYT-C; $n=5)$, and PBS-kindled $(P B S ; n=6)$ animals. $B$, The mean number of stimulations to reach a stage 5 seizure was calculated for all groups, and data were subjected to a one-way ANOVA with post hoc Tukey tests. NGF-infused rats $(N G F ; n=7)$ required $\sim 45 \%$ fewer stimulations to reach a stage 5 seizure, as compared with rats infused with PBS $(P B S ; n=6)$ or cytochrome C $(C Y T-C ; n=$ 5) $(p<0.05)$. Values represent the mean number of stimulations \pm SEM required to reach a stage 5 seizure.

and NGF-infused kindled groups as a function of stimulation number. There was a marked acceleration in the behavioral progression of kindling in the NGF-infused rats relative to PBSand cytochrome $\mathrm{C}$-infused rats $(p<0.001$; Fig. $1 A)$. Post hoc analyses revealed no difference in the behavioral progression of kindling between the PBS and cytochrome-C groups $(p>0.05)$. The mean number of stimulations to reach a stage 5 seizure also was calculated for all groups, and data were subjected to a one-way ANOVA with post hoc Tukey tests. On average, NGFtreated rats required $\sim 45 \%$ fewer stimulations (mean $=8.28 \pm$ 1.01) to reach a stage 5 seizure, as compared with the kindled PBS and cytochrome $\mathrm{C}$ groups (combined mean $=14.92 \pm 0.91$; Fig. $1 B)$. By the end of the kindling paradigm, all rats had shown at least three stage 5 seizures.

\section{AD duration analyses}

A repeated measures ANOVA was conducted to evaluate AD duration as a function of stimulation number. As expected, AD duration significantly increased as a function of stimulation number across all groups $(p<0.001$; data not shown). AD duration as a function of stimulation number did not differ among the groups $(p>0.05)$. In addition, a one-way ANOVA revealed that there were no differences in the cumulative durations of ADs among the groups $(p>0.05$; data not shown).

\section{Mossy fiber sprouting analyses}

NGF inf usions increased Timm staining in the stratum oriens (Fig. 2) and IML of kindled animals (Fig. 4). A three-way ANOVA [ $3 \times$ $(2 \times 16)]$ with one between variable (Group) and two within variables [Brain Hemisphere (left or right) and Cursor Position (1-16, starting at the hilus)] was conducted for the analysis of Timm densitometry in the CA3 region. Analyses were done both on raw densitometry measures and on measures corrected for background density. The results were nearly identical. Statistical analyses revealed no differences in density of background staining in the stratum radiatum across all groups, indicating that there was no influence of seizure activity on the staining in the stratum radiatum. There was a main effect for Cursor Position $(p<0.001)$, showing that the density of Timm granules was greatest in the hippocampal CA3 area near the hilus and decreased with increasing distance from the hilus in all animals (Fig. 2). This main effect was qualified further by a significant Group $\times$ Cursor Position interaction $(p<0.001)$. Post hoc analyses revealed that Timm granule density was enhanced significantly in the kindled groups (upper curves, Fig. $3 B$ ) relative to all nonkindled control groups (lower curves, Fig. $3 B)(p<0.05)$. This enhancement was increased further in the NGF-kindled group (topmost curve, Fig. $3 B$ ), as compared with the kindled-PBS and cytochrome $\mathrm{C}$ groups $(p<$ $0.05)$. Timm granule density in the CA3 region of the NGF-infused nonkindled condition was decreased relative to the other nonkindled infused controls. However, because the Timm staining of this group was completed at a later date than the other five groups, these results may not be representative and should be interpreted with caution.

A four-way ANOVA $[6 \times(6 \times 2 \times 9)]$ with one between variable (Group) and three within variables [Section (1-6 ventral to dorsal), Brain Hemisphere (left or right), and Cursor Position (1-9)] was conducted for the analysis of Timm density in the IML region. There was a main effect for Group $(p<0.05)$. Preliminary analyses revealed no differences between the kindled controlinf used groups (PBS and cytochrome C) and among all nonkindled groups (NGF, PBS, and cytochrome C). Thus, for graphical presentation, data for these respective groups were combined and analyzed (Fig. 5B). Post hoc analyses revealed increased Timm granule density in the NGF-infused kindled group, as compared with the kindled control-infused groups $(p<0.05)$ and all nonkindled groups $(p<0.01)$. However, there were no significant differences in Timm granule density in the IML region between the kindled control-infused groups and nonkindled groups $(p>0.05)$.

\section{Hilar neuronal density analyses}

For analysis of hilar neuronal density, a three-way ANOVA [ $3 \times$ $(2 \times 6)]$ with one between variable (Group) and two within variables [Brain Hemisphere (left or right) and Brain Section Depth (1-6, ventral to dorsal)] was conducted. Evaluations of hilar neuronal density were performed at the same horizontal levels as the Timm analyses. Analyses revealed a main effect for Brain Section Depth $(p<0.001)$, confirming the findings of Spiller and Racine (1994), showing that neuronal density is higher in more ventral brain sections than in more dorsal brain sections. For data presentation, however, cell density data were collapsed across section level and were presented as a measure of mean 


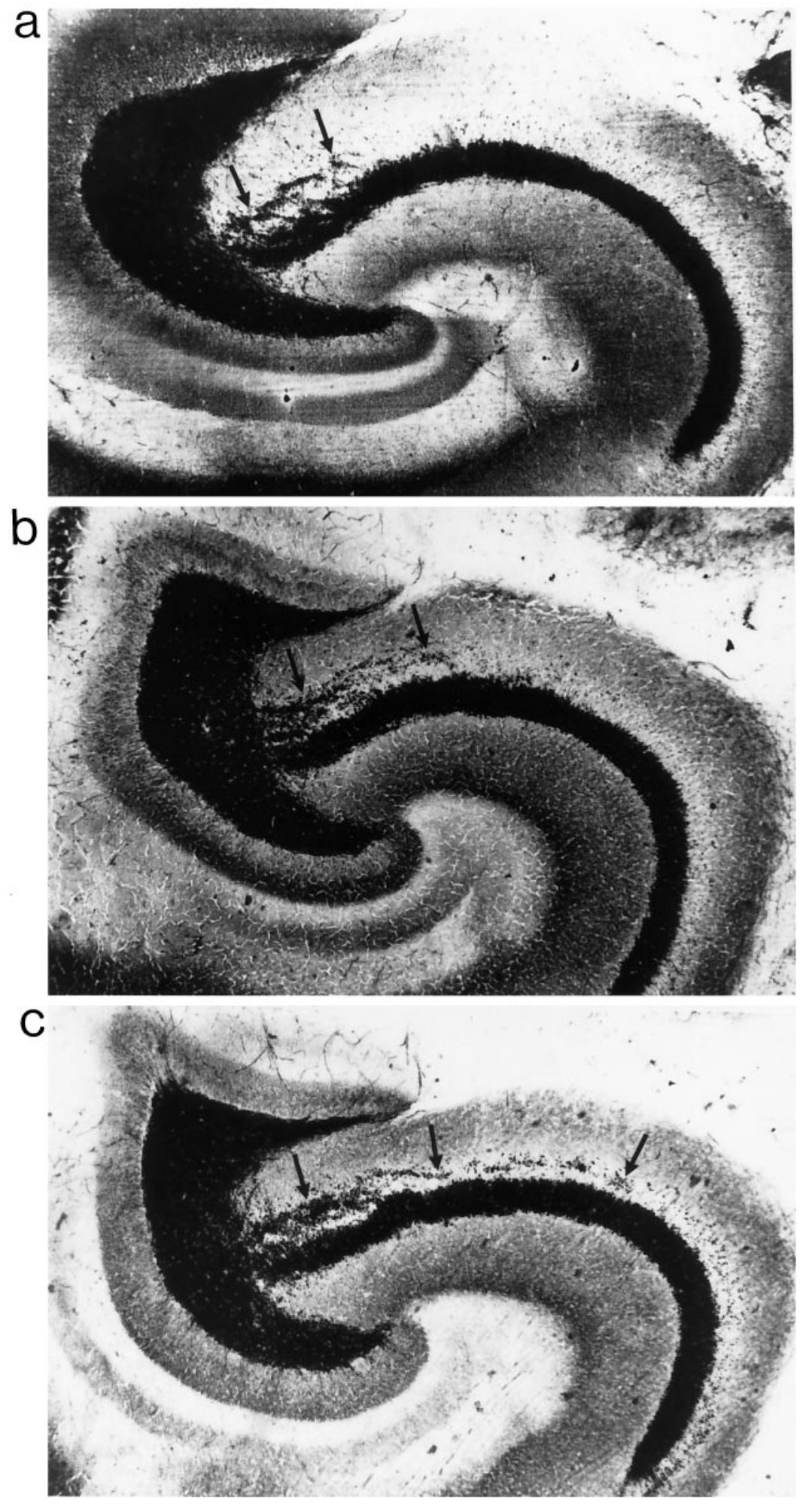

Figure 2. Timm staining and kindling-induced synaptic reorganization in CA3 region induced by amygdala kindling. Shown are representative examples of area CA3 of a nonkindled PBS-infused rat $(a)$, a kindled PBS-inf used rat $(b)$, and a kindled NGF-infused rat $(c)$. Arrows point to Timm granules in the stratum oriens of the CA3. neuronal density. Orthogonal comparisons revealed that mean neuronal densities were $\sim 15 \%$ lower in the kindled controlinfused rats compared with all the nonkindled rats and the kindled NGF-infused rats $(p<0.05$; Fig. 6$)$. There was also a main effect for Group ( $p<0.02$; data not shown).

\section{Morphometric analyses}

To evaluate the possibility that the observed reduction in mean hilar neuron density may be attributable to a kindling-induced increase in hilar area rather than an actual neuron loss, we conducted a three-way ANOVA $[3 \times(2 \times 6)]$ with one between variable (Group) and two within variables [Brain Hemisphere (left or right) and Brain Section Depth (1-6, ventral to dorsal)] to evaluate hilar area. Area was defined as shown in Figure $7 A$. There was a main effect for Group $(p<0.05)$, and post hoc analyses showed that seizure activity increased the area of the hilus in the kindled PBS and cytochrome C-infused groups, as 

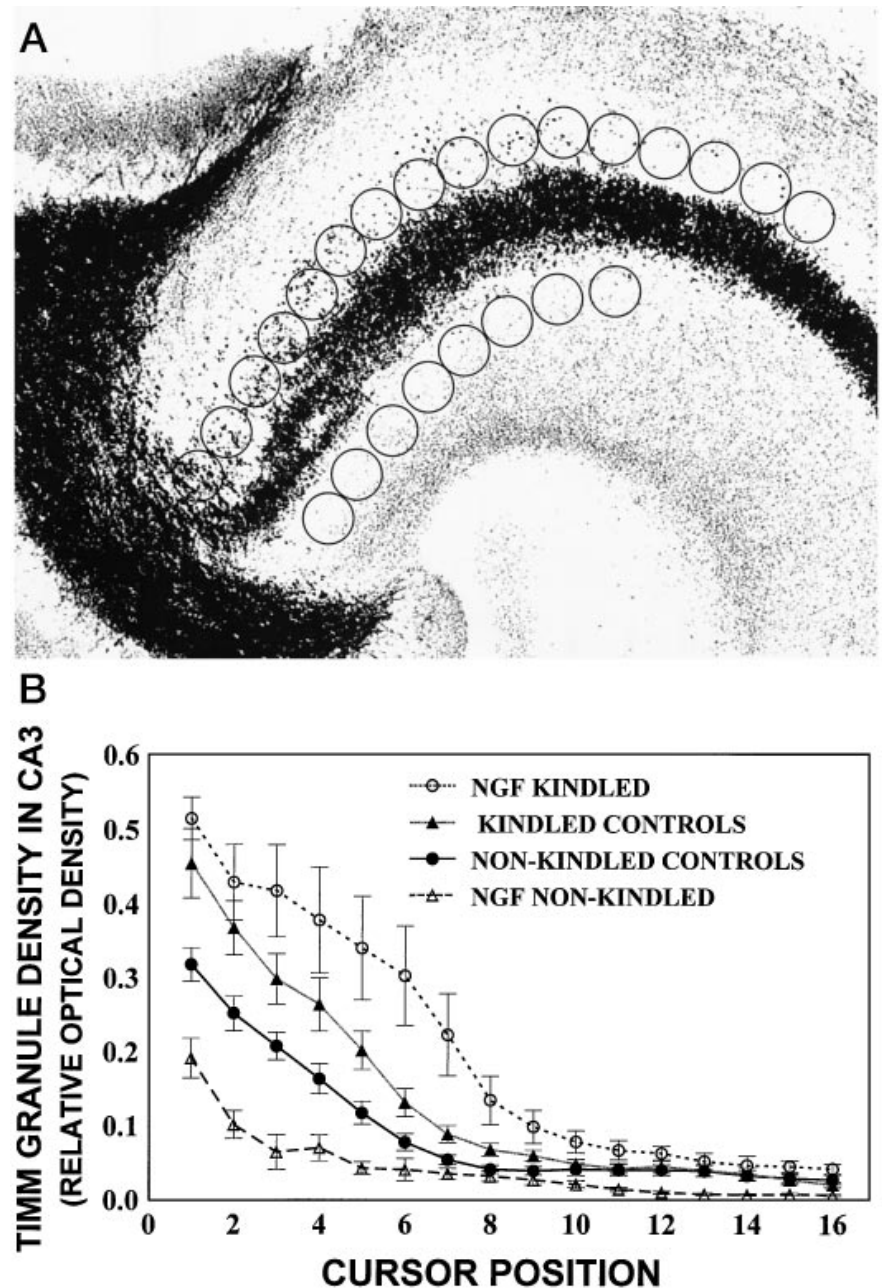

(numbers increase with increasing distance from hilus)

Figure 3. A, Digitized image of the hippocampal CA3 region. The density measurements of Timm granules were performed by placing an open circle cursor $\left(1.3 \mathrm{~cm}^{2}\right)$ at 16 adjacent positions along the stratum oriens starting adjacent to the hilar region. Eight cursors were placed in the stratum radiatum adjacent to the hilar region and provided the background staining density. Note that cursor windows for background measures in the stratum radiatum were clearly out of the mossy fiber tracts. $B$, Timm granule density in the CA3 region expressed as relative optical density (ROD) as a function of cursor position for all groups. Nonkindled and kindled control groups contain combined data for cytochrome $\mathrm{C}$ and PBS groups, because no differences were found among these groups by a three-way ANOVA and subsequent post hoc comparisons $(p>0.05)$. Similarly, no differences in Timm granule density from ipsilateral and contralateral hippocampi were found $(p>0.05)$, so data were combined for graphical presentation. Values represent mean ROD as a function of cursor position \pm SEM for the NGF-kindled group $(n=$ 7), kindled control group (PBS-infused, $n=6$; cytochrome C-infused, $n=5$ ), nonkindled control group (PBS-infused, $n=7$; cytochrome C-inf used, $n=6)$, and NGF-inf used nonkindled group $(n=5)$. There was a main effect for Cursor Position $(p<0.001)$, showing that the density of Timm granules was greatest in the hippocampal CA3 area near the hilus and decreased with increasing distance from the hilus in all animals. This main effect was qualified further by a significant Group $\times$ Cursor Position interaction $(p<0.001)$. Post hoc analyses revealed that Timm granule density was increased in the kindled groups (upper curves), as compared with all nonkindled groups (lower curves; $p<0.05$ ). This enhancement was increased further in the NGF-kindled group (topmost curve), as compared with the other kindled conditions $(p<0.05)$.
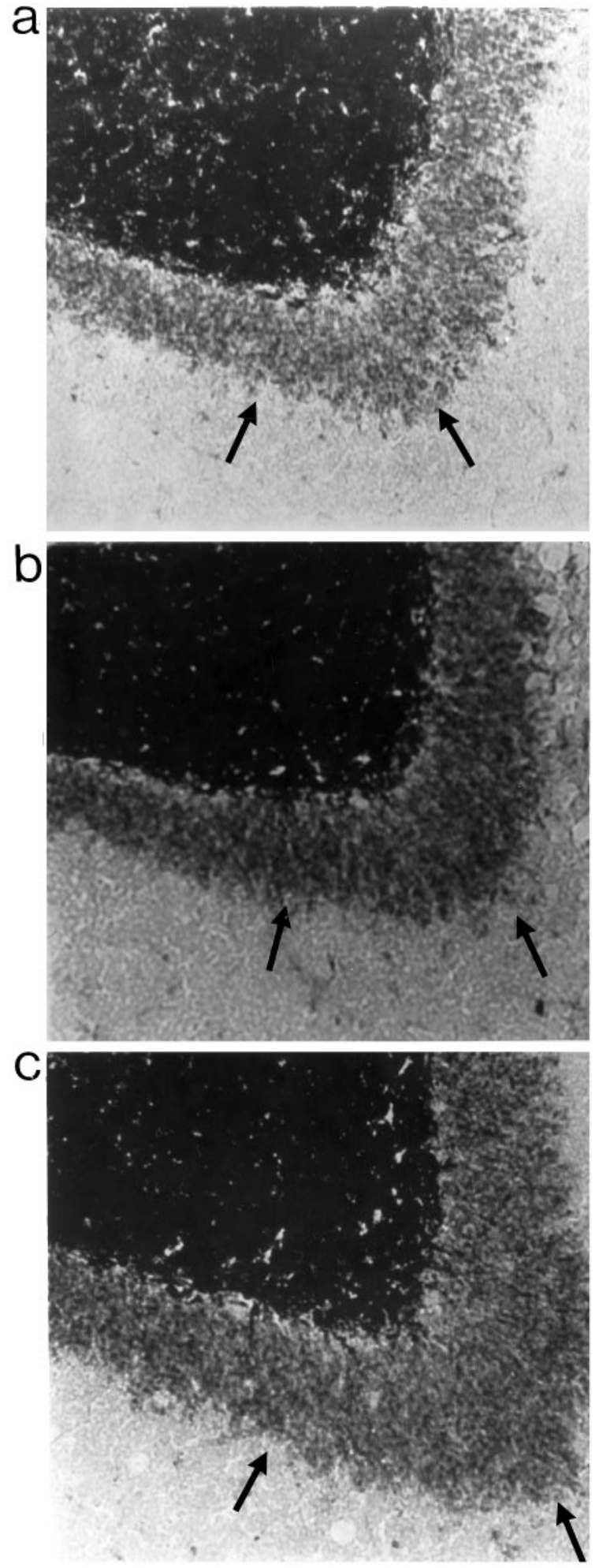

Figure 4. Timm staining in IML region. A, Representative examples of IML region of a nonkindled PBS-infused rat $(a)$, a kindled PBS-infused rat $(b)$, and a kindled NGF-inf used rat $(c)$. Arrows point to Timm granules in the IML region.

compared with the PBS-nonkindled condition ( $p<0.05$; Fig. $7 B)$. There was also a significant main effect for section level: $F_{(5,160)}=$ 22.97, $p<0.001$, indicating that hilar area was greater in more ventral sections, as compared with more dorsal sections (data not 


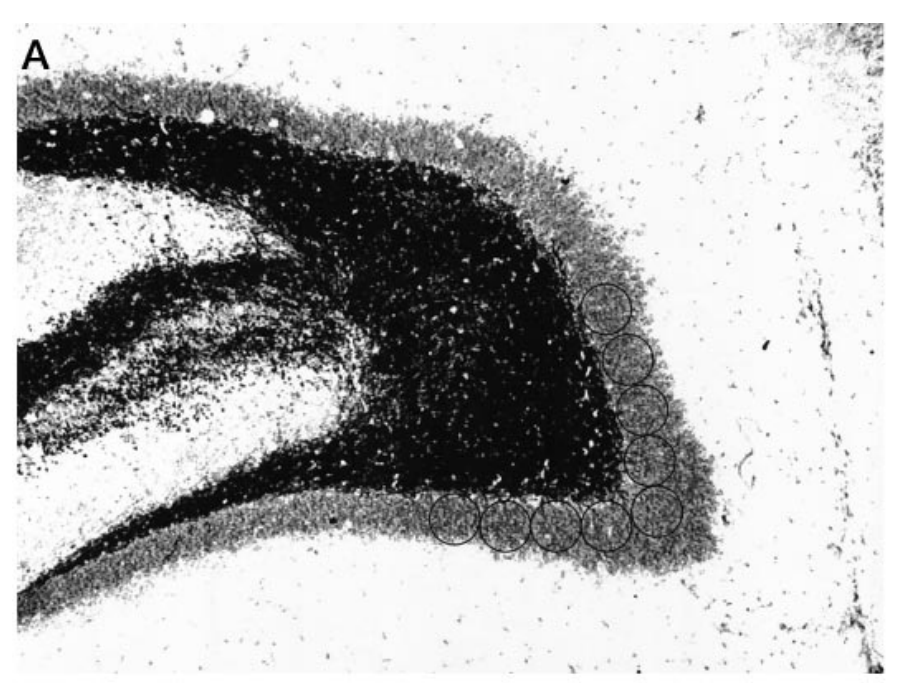

B

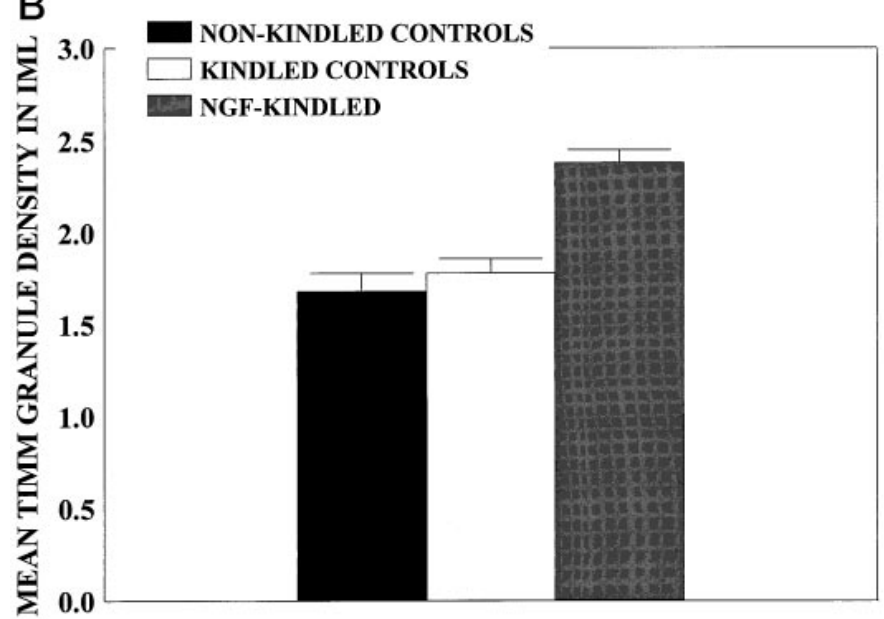

Figure 5. A, Digitized image of the IML region. Density of Timm granules in IML region was measured at nine adjacent cursor positions by placing one cursor above the genu of the hilus and four cursor positions to the right and left of this cursor. Background values were provided as described in Figure $3 A$. $B$, Timm granule density in IML region expressed as ROD for kindled-infused controls $(n=11)$, nonkindled-infused controls $(n=18)$, and the NGF-infused kindled group $(n=6)$. Timm granule density was increased in the NGF-kindled group relative to the kindled control group $(p<0.05)$ and the nonkindled group $(p<0.01)$. Values represent mean Timm granule density (ROD) as a function of group \pm SEM.

shown). These findings implicate kindling-induced increases in hilar area rather than hilar cell loss as an explanation for the decrease in hilar cell density. In any event, the administration of NGF before and during kindling appeared to attenuate these kindling-induced hilar changes, whether measured by neuronal density (Fig. 6) or by mean hilar area ( $p>0.05$; Fig. $7 B)$.

\section{DISCUSSION}

Intraventricular administration of nerve growth factor was shown to accelerate epileptogenesis and enhance kindlinginduced sprouting of mossy fibers from dentate granule cells in the hippocampus, without any evidence of an associated loss in hilar neuron numbers. These findings seem to exclude the possibility that the mossy fiber sprouting is triggered by a partial deafferentation of the target region. Instead, we favor the interpretation that kindling-induced mossy fiber sprouting

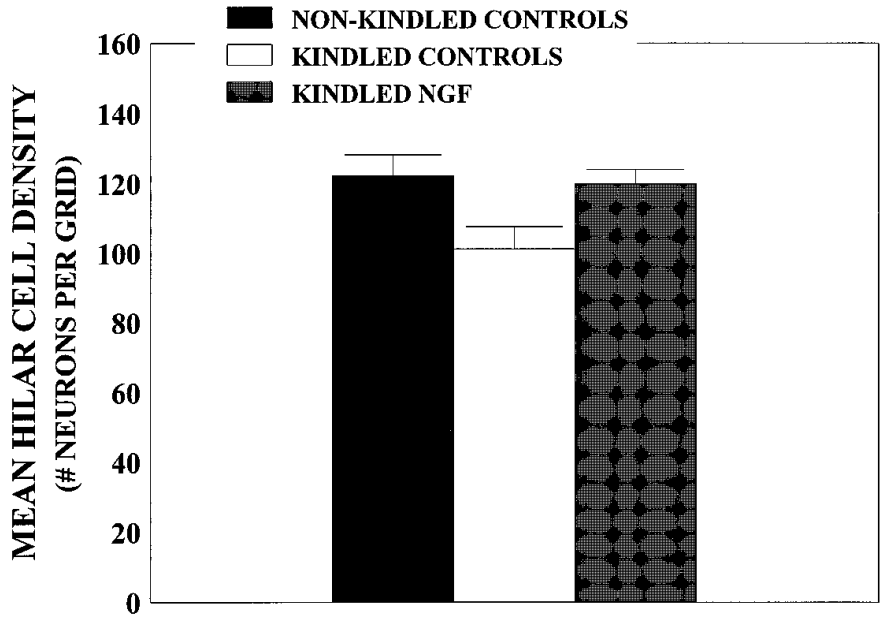

Figure 6. Neuronal density counts in the hilar region. $A$, Mean hilar neuronal density as a function of group. A three-way ANOVA and subsequent post hoc comparisons revealed no differences among the nonkindled PBS $(n=7)$, cytochrome C $(n=6)$, and NGF $(n=5)$ groups (nonkindled controls; $p>0.05)$ and no differences between the kindled PBS $(n=6)$ and cytochrome $\mathrm{C}(n=5)$ groups (kindled controls) $(p>0.05)$. Data for these nonkindled and kindled animals were combined, respectively. Values represent mean hilar cell density \pm SEM. Mean hilar cell density was decreased by $\sim 15 \%$ in the kindled control group relative to both the nonkindled animals and the kindled NGF-infused group $(n=7 ; p<0.05)$.

is dependent on the coinvolvement of neuronal activation and growth factors such as NGF.

\section{Coinvolvement of neuronal activity and activation- induced upregulation of growth factors in the regulation of mossy fiber sprouting}

There is evidence that the high levels of neuronal activity occurring during seizures are associated with changes in gene expression (Morgan and Curran, 1991). For example, seizure activity induces the transcriptional activation of a number of immediate early genes (Morgan and Curran, 1991; Kiessling and Gass, 1993; Labiner et al., 1993), followed by the expression in the dentate granule cells of genes encoding neurotrophic factors (Gall and Isackson, 1989; Ernfors et al., 1991; Gall, 1993; Gall et al., 1994), neurotrophic factor receptors (Bengzon et al., 1993; Bugra et al., 1994), and axonal growth-associated proteins (Bendotti et al., 1993; Meberg et al., 1993). This raises the possibility that activation-induced transcriptional regulation of gene expression in the dentate granule cells may play a critical role in the development of mossy fiber sprouting by initiating a chain of molecular events culminating in neural growth (Morgan and Curran, 1991). In the present study NGF alone does not appear to be sufficient to trigger sprouting in this system.

This concept of a coinvolvement of neuronal activation and growth factors in the regulation of sprouting has been well documented in the peripheral nervous system (Diamond et al., 1992). Specifically, it has been demonstrated that NGF was responsible for the initiation and maintenance of the collateral sprouting of cutaneous nociceptive sensory axons in rats, that impulse activity in the same neurons dramatically accelerated the onset of the NGF-driven sprouting, and that this action of nerve impulses was dependent on the presence of endogenous NGF (Diamond et al., 1992). This suggests that the action of nerve impulses, combined with the presence of endogenous NGF, may be to prime the cellular mechanisms that initiate the sprouting response (Diamond et al., 1992). The results obtained in the present study 


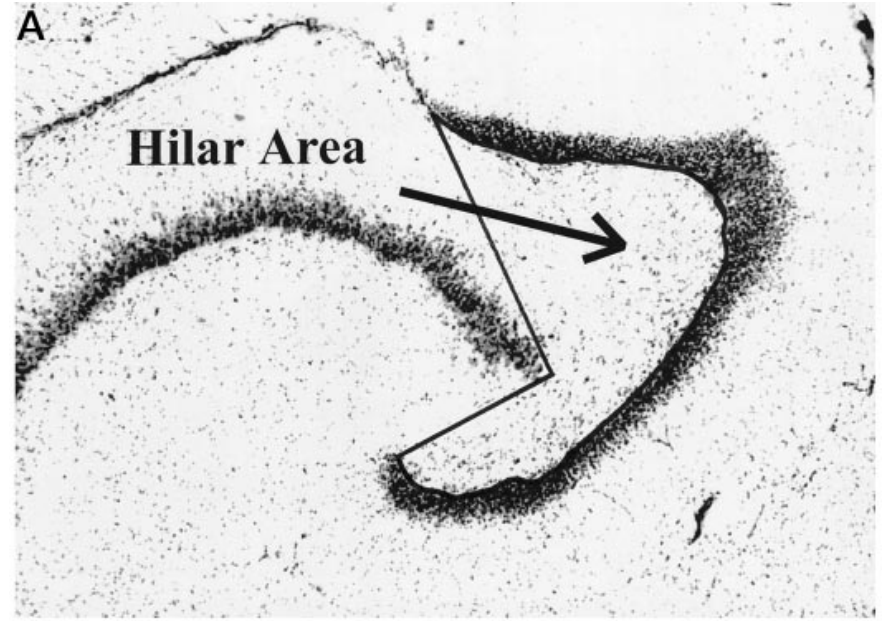

B

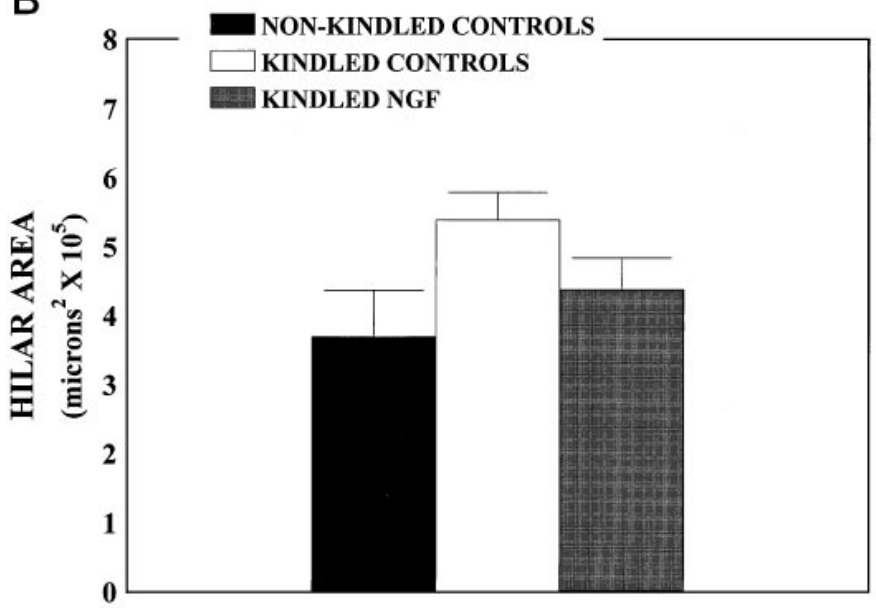

Figure 7. Hilar area measurements. A, Hilar area outlined by thick line, using the MCID image analysis system. Hilar area was defined by the inner edge of the granule cell layer and the lines connecting the tips of the two granule cell blades to the beginning of the pyramidal cell layer of Ammon's horn. Cresyl violet-stained sections used for the determination of neuronal density also were used for hilar area measurements. $B$, Mean hilar area as a function of treatment condition. A three-way ANOVA and subsequent post hoc comparisons revealed no differences among the nonkindled PBS $(n=7)$, cytochrome $\mathrm{C}(n=6)$, and NGF groups $(n=5$, nonkindled controls) $(p>0.05)$ and no differences between the kindled PBS $(n=6)$ and cytochrome $\mathrm{C}(n=5)$ groups (kindled controls) ( $p>0.05)$. Data for these nonkindled and kindled animals were combined, respectively. Values represent mean hilar area expressed in $\mu \mathrm{m}^{2} \pm$ SEM. Mean hilar cell area was increased by $\sim 15 \%$ in the kindled control group relative to the nonkindled animals and the kindled NGF group $(n=7 ; p<0.05)$.

parallel these earlier findings and raise the possibility that a comparable mechanism may exist in the CNS. Seizure activity upregulates a number of different neurotrophic factors, however, and it is unlikely that NGF is the only growth factor contributing to activation-induced mossy fiber sprouting in the kindling model.

\section{Potential mechanism for increased kindling rates and enhanced mossy fiber sprouting after NGF administration}

Our findings that NGF administration accelerates kindling rates and enhances mossy fiber sprouting are compatible with those of Van der Zee et al. (1995) and Rashid et al. (1995), who demonstrated that intraventricular infusion of NGF inhibitors retards kindling rates and reduces mossy fiber sprouting. Taken together, these findings indicate that NGF plays an important role in regu- lating the development of kindling and kindling-induced neural growth. It is not yet clear how NGF mediates these effects. It has been established that the biological effects of NGF are mediated primarily via its high-affinity receptor, TrkA (Kaplan et al., 1991; Klein et al., 1990; Chao, 1992), but expression of these receptors is most pronounced in the cholinergic neurons in the basal forebrain. At present there is little evidence for TrkA receptors in the hippocampus (Holtzman et al., 1995) (but see Cellerino, 1995). NGF also binds to the low-affinity p75 receptor (Bothwell, 1991), and p75 receptor immunoreactivity has been reported in both the CA3 hippocampal pyramidal layer and the dentate gyrus of colchicinetreated animals (Pioro and Cuello, 1990). It is still controversial whether the p75 receptor is capable of mediating the biological effects of NGF, but cooperative interactions with Trk receptors to increase affinity of neurotrophin binding and signaling efficiency, as well as a role in apoptosis, seem likely (Chao and Hempstead, 1995). Thus, it remains unclear whether NGF can mediate its effects directly on hippocampal neurons.

Alternatively, it is possible that NGF acts indirectly via the high-affinity TrkA receptors on cholinergic neurons in the basal forebrain. It is well established that these neurons are sensitive to NGF. Specifically, intraventricularly injected ${ }^{125}$ I-NGF labels cholinergic neurons (Nishio et al., 1992), chronic intraventricular administration of NGF increases both choline acetyltransferase (ChAT) activity and high-affinity choline transport in the rat brain (Hefti et al., 1984), and exogenous NGF promotes axonal outgrowth in the lesioned septohippocampal pathway (Hagg et al., 1990). By contrast, anti-NGF inf usion blocks cholinergic sprouting after kainic acid administration (Holtzman and Lowenstein, 1995), blocks the collateral sprouting of hippocampal fibers after entorhinal cortex lesions (Van der Zee et al., 1992), and reduces ChAT immunostaining in basal forebrain cholinergic neurons (Van der Zee et al., 1995). These same cholinergic systems are involved in kindling (Arnold et al., 1973; Cain, 1989), and cholinergic antagonists have been shown to retard the development of kindling in a dose-dependent manner (Arnold et al., 1973; Westerberg and Corcoran, 1987). Thus, an enhanced synthesis of acetylcholine in basal forebrain neurons induced by NGF infusions could lead to increased kindling rates. Whether such increases in acetylcholine synthesis could affect mossy fiber sprouting remains to be determined. So that we can address this issue, a systematic evaluation of the effects of cholinergic agonists and antagonists on kindlinginduced mossy fiber sprouting is in progress.

\section{Kindling-induced decreases in neuronal density versus kindling-induced increases in hilar area}

There is some debate in the literature regarding whether kindling produces genuine hilar neuronal loss (Cavazos and Sutula, 1990) or whether kindling, by causing an increase in hilar area with a corresponding decrease in neuronal density, leads only to an apparent hilar neuronal loss (Bertram and Lothman, 1993; Watanabe et al., 1996). In the present study we showed that, although amygdala kindling twice a day for $11 \mathrm{~d}$ significantly decreased neuronal density in the hilus by $\sim 15 \%$, the hilar area also was increased significantly by approximately the same amount. This result fails to support the hypothesis that kindling produces hilar cell loss. It is more likely that amygdaloid kindling induces a structural change that leads to an increase in hilar area. It remains to be determined whether or not this hilar change is permanent.

The possibility that there is a more subtle form of kindlinginduced denervation of synaptic targets cannot be excluded. One 


\begin{tabular}{|c|c|c|c|c|c|}
\hline Condition & $\begin{array}{l}\text { Kindling } \\
\text { rate }\end{array}$ & $\begin{array}{l}\text { Sprouting } \\
\text { (CA3 region) }\end{array}$ & $\begin{array}{l}\text { Sprouting } \\
\text { (IML) }\end{array}$ & $\begin{array}{l}\text { Hilar neuronal } \\
\text { density }\end{array}$ & $\begin{array}{l}\text { Hilar } \\
\text { area }\end{array}$ \\
\hline Nonkindled control & N/A & - & - & - & - \\
\hline Nonkindled NGF & N/A & $\downarrow$ & - & - & - \\
\hline Kindled control & - & $\uparrow$ & - & $\downarrow$ & $\uparrow$ \\
\hline Kindled NGF & $\uparrow$ & $\uparrow \uparrow$ & $\uparrow \uparrow$ & - & - \\
\hline
\end{tabular}

other major source of input to the inner molecular layer is the cholinergic septodentate afferents. Given that TrkA expression in the hippocampus is limited primarily to these cholinergic fibers (Holtzman et al., 1994, 1995), they would not be expected to suffer as a consequence of the NGF infusions. Although the cause of the kindling-induced hilar area increases is unclear (Bertram and Lothman, 1993; Watanabe et al., 1996), it has been suggested that they could result from a number of causes, including increases in the dendritic tree, branching of axon terminals, increases in the size or number of glial cells (Bertram and Lothman, 1993; Watanabe et al., 1996), or an accumulation of fluid in the extracellular or intracellular space (Watanabe et al., 1996). In fact, astrocyte hypertrophy has been reported in the hilar region as a result of amygdala kindling (Khurgel et al., 1992). Thus, it is possible that glial cell changes (i.e., hypertrophy or proliferation) may underlie the observed kindling-induced increases in hilar area. We currently are investigating this possibility. Interestingly, in the present study we found no kindling-induced decrease in neuronal density or increase in hilar area in the kindled group inf used with NGF. These findings suggest that NGF may exert an overall stabilizing or protective role in the hilus. Additional experiments are required to investigate the mechanisms underlying this effect.

\section{Mossy fiber sprouting as a potential mechanism for epileptogenesis}

As outlined earlier, kindling produces a permanently enhanced sensitivity to electrical stimulation that is accompanied by lasting mossy fiber sprouting (Sutula et al., 1988; Represa et al., 1993). The activity dependence of this kindling-induced mossy fiber sprouting has been demonstrated by its preferential induction by highfrequency, as opposed to low-frequency, stimulation (Sutula et al., 1988). The consequences of kindling-induced mossy fiber sprouting are unclear, but it has been proposed that this sprouting could explain the development and maintenance of epileptogenesis by the creation of recurrent excitatory circuits that promote the progression and the maintenance of kindling (Sutula et al., 1988; Cronin et al., 1992; Okazaki et al., 1995). Our results are consistent with such a mechanism. Although epileptogenic effects can develop much more rapidly than mossy fiber sprouting, as demonstrated by Timm staining (Cavazos et al., 1991), this technique might fail to reveal, for example, a rapid synaptic reorganization (Geinisman et al., 1992). Regardless, an interaction between neuronal activation and activation-induced upregulation of growth factors in the regulation of sprouting (Diamond et al., 1992) is appealing as one basis of neuronal plasticity in the adult nervous system, given that such an interaction potentially can contribute to long-term structural and functional changes in the brain.

Kindling-induced mossy fiber sprouting has been reported in both the CA3 (Represa and Ben-Ari, 1992; Van der Zee et al., 1995) and the IML regions of the hippocampus (Sutula et al., 1988; Watanabe et al., 1996). In the present study there was no evidence of kindling-induced mossy fiber sprouting in the IML region in the kindled control groups, as compared with the nonkindled controls. The appearance of IML sprouting in the group that received both kindling stimulations and NGF suggests that our procedures may be near threshold for kindling-induced IML sprouting. This indicates that CA3 sprouting may show a reliably lower threshold than IML sprouting.

In summary, our findings indicate that NGF plays an important role in the development of kindling and kindling-induced mossy fiber sprouting (see Table 1 for a summary of the findings). We suggest that kindling-induced mossy fiber sprouting is attributable to the coinvolvement of neuronal activation and activation-induced upregulation of growth factors, as opposed to kindling-induced cell loss, and that this sprouting contributes to lasting modifications of neural structure and function in the epileptic brain.

\section{REFERENCES}

Arnold PS, Racine RJ, Wise RA (1973) Effects of atropine, reserpine, 6-hydroxydopamine, and handling on seizure development in the rat. Exp Neurol 40:457-470.

Bendotti C, Vezzani A, Tarizzo G, Samanin R (1993) Increased expression of GAP-43, somatostatin, and neuropeptide Y mRNA in the hippocampus during development of hippocampal kindling in rats. Eur J Neurosci 5:1312-1320.

Bengzon J, Soderstrom S, Kokaia Z, Kokaia M, Ernfors P, Persson H, Ebendal T, Lindvall O (1992) Widespread increase of nerve growth factor protein in the rat forebrain after kindling-induced seizures. Brain Res 587:338-342.

Bengzon J, Kokaia Z, Ernfors P, Kokaia M, Leanza G, Nilsson OG, Persson H, Lindvall O (1993) Regulation of neurotrophin and trkA and trkC tyrosine kinase receptor messenger RNA expression in kindling. Neuroscience 53:433-436.

Bertram EH, Lothman EW (1993) Morphometric effects of intermittent kindled seizures and limbic status epilepticus in the dentate gyrus of the rat. Brain Res 603:25-31.

Bothwell M (1991) Keeping track of neurotrophin receptors. Cell 65:915-918.

Bugra K, Pollard H, Charton G, Moreau J, Ben-Ari Y, Khrestchatisky M (1994) aFGF, bFGF, and flg mRNAs show distinct patterns of induction in the hippocampus following kainate-induced seizures. Eur J Neurosci 6:58-66.

Cain DP (1989) Excitatory neurotransmitters in kindling: excitatory amino acid, cholinergic, and opiate mechanisms. Neurosci Biobehav Rev 13:269-276.

Cavazos JE, Sutula JP (1990) Progressive neuronal loss induced by kindling: a possible mechanism for mossy fiber synaptic reorganization and hippocampal sclerosis. Brain Res 527:1-6.

Cavazos JE, Golarai G, Sutula T (1991) Mossy fiber sprouting reorganization induced by kindling: time course, development, progression, and permanence. J Neurosci 11:2795-2803.

Cavazos JE, Das I, Sutula TP (1994) Neuronal loss induced in limbic pathways by kindling: evidence for induction of hippocampal sclerosis by repeated brief seizures. J Neurosci 14:3106-3121.

Cellerino A (1995) Expression of mRNA coding for the nerve growth factor receptor trkA in the hippocampus of the adult rat. Neuroscience 70:613-616.

Chao M (1992) Neurotrophin receptors: a window into neuronal differentiation. Neuron 9:583-593.

Chao MV, Hempstead BL (1995) P75 and Trk: a two receptor system. Trends Neurosci 18:321-326. 
Coughlin MD, Collins MB (1985) Nerve growth factor independent development of mouse embryonic sympathetic neurons in dissociated cell culture. Dev Biol 110:392-410.

Cronin J, Obenaur A, Houser CR, Dudek FE (1992) Electrophysiology of dentate granule cells after kainate-induced synaptic reorganization of the mossy fibers. Brain Res 573:302-310.

Diamond J (1982) Modeling and competition in the nervous system: clues from the sensory innervation of skin. In: Current topics in developmental biology, Vol 17 (Moscana AA, Monroy A, eds), pp 147-205. New York: Academic.

Diamond J, Cooper E, Turner C, Macintyre L (1976) Trophic regulation of nerve sprouting. Science 193:371-377.

Diamond J, Coughlin M, Holmes M (1992) Endogenous NGF and nerve impulses regulate the collateral sprouting of sensory axons in the skin of the adult rat. J Neurosci 12:1454-1466.

Eide FF, Lowenstein DH, Reichardt LF (1993) Neurotrophins and their receptors-current concepts and implications for neurologic disease. Exp Neurol 121:200-214.

Ernfors P, Bengzon J, Kokaia Z, Persson H, Lindvall O (1991) Increased levels of messenger RNAs for neurotrophic factors during kindling epileptogenesis. Neuron 7:164-176.

Funabashi T, Sasaki H, Kimura F (1988) Intraventricular injection of antiserum to nerve growth factor delays the development of amygdaloid kindling. Brain Res 458:132-136.

Gall CM (1993) Seizure-induced changes in neurotrophin expression: implications for epilepsy. Exp Neurol 124:150-166.

Gall CM, Isackson PJ (1989) Limbic seizures increase neuronal production of messenger RNA for nerve growth factor. Science 245:758-761.

Gall CM, Berschauer R, Isackson PJ (1994) Seizures increase basic fibroblast growth factor mRNA in adult rat forebrain neurons and glia. Mol Brain Res 21:190-205.

Geinisman Y, Morell F, deToledo-Morell L (1992) Increase in the number of axospinous synapses with segmented postsynaptic densities following hippocampal kindling. Brain Res 569:341-347.

Goddard G, McIntyre D, Leech C (1969) A permanent change in brain function resulting from daily electrical stimulation. Exp Neurol 245:745-761.

Hagg T, Vahlsing HL, Manthorpe M, Varon S (1990) Nerve growth factor infusion into the denervated adult rat hippocampal formation promotes its cholinergic reinnervation. J Neurosci 10:3087-3092.

Hefti F, Dravid A, Hartikka J (1984) Chronic intraventricular injections of nerve growth factor elevate hippocampal choline acetyltransferase activity in adult rats with partial septohippocampal lesions. Brain Res 293:305-309.

Holtzman D, Lowenstein DH (1995) Selective inhibition of axon outgrowth by antibodies to NGF in a model of temporal lobe epilepsy. J Neurosci 15:7062-7070.

Holtzman D, Kilbridge J, Li Y, Cunningham ET, Lenn NJ, Clary DO, Reichardt R, Mobley WC (1995) TrkA expression in the CNS: evidence for the existence of several novel NGF-responsive CNS neurons. J Neurosci 15:1527-1576.

Ip AN, Li Y, Yancopoulos GD, Lindsay RM (1993) Cultured hippocampal neurons show responses to BDNF, NT-3, and NT-4 but not NGF. J Neurosci 13:3394-3405.

Kaplan D, Hempstead B, Martin-Zanca D, Chao M, Parada L (1991) The trk proto-oncogene product: a signal-transducing receptor for nerve growth factor. Science 252:554-558.

Khurgel M, Racine RJ, Ivy GO (1992) Kindling causes changes in the composition of the astrocytic cytoskeleton. Brain Res 592:338-342.

Kiessling M, Gass P (1993) Immediate early gene expression in experimental epilepsy. Brain Pathol 3:381-393.

Klein R, Conway D, Parada L, Barbacid M (1990) The trkB tyrosine kinase gene codes for a second neurogenic receptor that lacks the catalytic kinase domain. Cell 61:647-656.

Labiner DM, Butler LS, Cao Z, Hosford DA, Shin C, McNamara JO (1993) Induction of $c$-fos mRNA by kindled seizures: complex relationship with neuronal burst firing. J Neurosci 13:1759-1769.

Mattson MP, Murrain M, Guthrie OB, Kater SB (1989) Fibroblast growth factor and glutamate: opposing roles in the generation and degeneration of hippocampal neuroarchitecture. J Neurosci 9:3728-3740.
Meberg PJ, Gall CM, Routtenberg A (1993) Induction of F1/GAP-43 gene: expression in hippocampal granule cells after seizures. Mol Brain Res 17:295-297.

Mobley WC, Schenker A, Shooter EM (1976) Characterization and isolation of proteolytically modified nerve growth factor. Biochemistry 15:5543-5551.

Morgan JI, Curran T (1991) Stimulus-transcription coupling in the nervous system: involvement of the inducible proto-oncogenes fos and jun. Annu Rev Neurosci 14:421-451.

Nishio T, Akiguchi I, Furukawa S (1992) Detailed distribution of nerve growth factor in rat brain determined by a highly sensitive enzyme immunoassay. Exp Neurol 116:76-84.

Patel MN, McNamara JO (1995) Selective enhancement of axonal branching in cultured dentate gyrus neurons by neurotrophic factors. Neuroscience 60:763-770.

Paxinos G, Watson C (1985) The rat brain in stereotaxic coordinates, 2nd Ed. Sydney: Academic.

Pinel JPJ, Rovner LI (1978) Electrode placement and kindling-induced epilepsy. Exp Neurol 58:335-346.

Pioro EP, Cuello AC (1990) Distribution of nerve growth factor-like immunoreactivity in adult rat central nervous system. Effect of colchicine and correlation with cholinergic system. II. Brainstem, cerebellum, and spinal cord. Neuroscience 34:89-110.

Okazaki MM, Evenson DA, Nadler JV (1995) Hippocampal mossy fiber sprouting and synapse formation after status epilepticus in rats: visualization after retrograde transport of biocytin. J Comp Neurol 352:515-534.

Racine RJ (1972) Modification of seizure activity by electrical stimulation. II. Motor seizure. Electroencephalogr Clin Neurophysiol 32: 281-294.

Rashid K, Van der Zee CEEM, Ross G, Chapman CA, Stanisz J, Riopelle R, Racine RJ, Fahnestock M (1995) A nerve growth factor peptide retards seizure development and inhibits neuronal sprouting in a rat model of epilepsy. Proc Natl Acad Sci USA 92:9495-9499.

Represa A, Ben-Ari Y (1992) Kindling is associated with the formation of novel mossy fibre synapses in the CA3 region. Exp Brain Res 92:69-78.

Represa A, LeGall La Salle G, Ben-Ari Y (1989) Hippocampal plasticity in the kindling model of epilepsy in rats. Neurosci Lett 99:345-350.

Represa A, Jorquera I, LeGall La Salle G, Ben-Ari Y (1993) Epilepsyinduced collateral sprouting of hippocampal mossy fibers: does it induce the development of ectopic synapses with granule cell dendrites? Hippocampus 3:258-268.

Spiller AE, Racine RJ (1994) Effect of kindling beyond the "stage 5" criterion on paired pulse depression and hilar cell counts in the dentate gyrus. Brain Res 635:139-147.

Sutula T, He XX, Cavazos J, Scott G (1988) Synaptic reorganization in the hippocampus induced by abnormal functional activity. Science 239:1147-1150.

Sutula T, Golarai G, Cavazos J (1992) Assessing the functional significance of mossy fiber sprouting. Epilepsy Res Suppl 7:251-259.

Vahlsing HL, Varon S, Hagg T, Fass-Holmes B, Dekker A, Manley M, Manthorpe M (1989) An improved device for continuous intraventricular infusions prevents introduction of pump-derived toxins and increases the effectiveness of NGF treatments. Exp Neurol 105:233-243.

Van der Zee CEEM, Fawcett J, Diamond J (1992) Antibody to NGF inhibits collateral sprouting of septohippocampal fibers following entorhinal cortex lesion in adult rats. J Comp Neurol 326:91-100.

Van der Zee CEEM, Rashid K, Le K, Moore K, Stanisz J, Diamond J, Racine RJ, Fahnestock M (1995) Intraventricular administration of antibodies to nerve growth factor retards kindling and blocks mossy fiber sprouting in adult rats. J Neurosci 15:5316-5323.

Watanabe Y, Johnson RS, Butler LS, Binder DK, Spiegelman BM, Papaioannou VM, McNamara JO (1996) Null mutation of c-fos impairs structural and functional plasticities in the kindling model of epilepsy. J Neurosci 16:3827-3836.

Westerberg V, Corcoran M (1987) Antagonism of central but not peripheral cholinergic receptors retards amygdala kindling in rats. Exp Neurol 95:194-206. 